Check for updates

The George Institute for Global Health, Imperial College London, UK

2 World Obesity Federation, London, UK

Cite this as: $B M J$ 2022;376:0576 http://dx.doi.org/10.1136/bmj.0576 Published: 04 March 2022

\section{Obesity action: Time to move from fragmentation and failure to solidarity and success}

\author{
To mark World Obesity Day Kent Buse and Johanna Ralston present a five point agenda to tackle a \\ maligned disease and a misunderstood public health emergency
}

\author{
Kent Buse, ${ }^{1}$ Johanna Ralston ${ }^{2}$
}

Scientists and other experts often seem to believe that "evidence speaks for itself." While that might at times be true, compelling evidence has been no guarantee for success when it comes to the continuing crisis of obesity. We have known for years that rates of obesity in children and adults have been increasing since the 1980 s (prevalence has doubled in over 70 countries since then)-with the most rapid rises in low- and middle-income countries (LMICs) as well as small island developing States (SIDS). ${ }^{1}$ The World Health Organisation's (WHO) targets on obesity set for 2025 are not only seriously off course, but rising rather than falling. The first ever Obesity-NCD Preparedness Ranking, published this week, reveals that many countries experiencing the biggest rise and highest numbers of people with obesity are also the most poorly positioned to deal with it, both as a disease and a driver of other non-communicable disease (NCDs), especially in LMICs. ${ }^{2}$

The reasons for this rise are multiple and best characterised by what Boyd Swindburn and colleagues termed obesogenic environments over 20 years ago-referring to the surroundings, opportunities, and conditions of life that impact on the food people eat and their opportunities for physical activity, layered on genetic predisposition, maternal health, and other drivers. ${ }^{3}$ An obesogenic environment includes the increased availability, accessibility, and affordability of energy-dense foods, along with intense promotion of such foods, particularly to children. Such conditions disproportionately affect the poor, who are rarely able to access or afford alternatives to what is available and heavily promoted in the immediate environment.

If evidence were enough, we would see the equivalent of a Marshall Plan to deal with this global crisis. We know obesity kills. It elevates the risk of cardiovascular disease (CVD), diabetes, cancer and a range of other conditions. It has been a major factor in who survives and who dies from covid-19. The economic impact of our collective neglect of obesity, linked to a lack of data as well as pervasive bias, is profound; a recent study found that if the status quo of obesogenic environments and exclusion of obesity from healthcare systems continues, the impact including healthcare costs and lost productivity will translate to $3.6 \%$ of GDP. ${ }^{4}$

Instead, the epidemic of obesity is consistently under-prioritised and misunderstood, while the people affected are stigmatised and subjected to weight bias. ${ }^{5} \mathrm{~A}$ narrative has been cynically constructed that individual irresponsibility and personal failure are to blame. ${ }^{6}$ This obfuscates the true roots of obesity-which include industry engineering of ultra processed foods, high in salt, sugar, and fats, to enhance their addictive properties and from which to generate greater financial returns..$^{8}$ The narrative is propped up by linking malconsumption to freedom of choice, individual liberty, and free trade. This has led to fragmented efforts and an absence of joined up, evidence-informed interventions that work.

While we don't expect a Marshall Plan for obesity, the time has come for WHO to lead efforts towards an ambitious, evidence-informed, and rights-based comprehensive Global Action Plan to address the drivers and responses to obesity from prevention to management. This Plan will support efforts to meet a range of health-related targets enshrined in the Sustainable Development Goals, NCD framework, and indeed WHO's own Triple Billion targets. Specifically, we suggest a five-point agenda: $A$ Global Action Plan.

We urge the World Health Assembly (WHA) when it recommendations on obesity and to request that WHO translates them into a Global Plan as proposed by France at the recent meeting of the Executive Board. ${ }^{9}$ Such a plan will need to be ambitious to accelerate action on the global targets that are faltering, be informed by people affected by obesity to ensure more integrated and holistic approaches, and outline independent accountability mechanisms which include people who are affected by obesity. Such a plan could also help increase coordination on obesity action, including at WHO itself where interest has been on the rise, but without a sufficiently integrated response to date. The World Obesity Federation and its members across the globe are ready to support the development of such an action plan.

\section{Coordinated national action}

It is governments that hold the key to whether the proposed plan will be implemented. Obesity's complex nature requires coordination and commitment across ministries and agencies. Stigma and misunderstanding have side lined obesity in health responses, and this must end.

\section{Action on the commercial actors who shape} obesogenic environments

A central job for governments is joined up action on the commercial determinants of obesity. These meets in May to adopt the draft global 
include the practices and products of firms and industries, but also the systems which facilitate and promote health harming environments. Failure to confront the social and commercial determinants will undermine meaningful change. Success will require a narrative shift away from individual responsibility to stronger state oversight of the environments which lead to obesity.

\section{Investment}

The investor community, which has brought about long term impacts with Environment, Social, and Governance (ESG) investment approaches, could play an important role in incentivising corporations to use their leverage to shift corporate practices from those which drive or neglect obesity to those that lead to healthier environments. ${ }^{10}$ Hence, we call for investment charter marks to include obesity-related considerations.

\section{A global movement}

These actions will be resisted by vested interests and mislabelled as impeding individual and trade freedoms. The disruption we are calling for requires a commitment to health and sustainability of the planet and a willingness to call out the institutions and individuals who will cut the lives (of others) short for profit. We must be crystal clear about who and what is cutting these lives short and to find ways to channel our collective anger into current social movements that are making governments wake up to the need for a major post-covid-19 reset. While the health movement has not yet mobilized for this kind of transformation; the climate movement is doing so. ${ }^{11}$ With shared interests in more sustainable approaches to healthcare, food, transport, decent work, participatory democracy and human rights, we must join forces. People with lived experience are key to this movement, as are youth.

Obesity policy has been underprioritised and fragmented for far too long. We must seize the opportunity of the upcoming World Health Assembly to demand more action and more results. Our immediate priority must be for WHO Member States to secure a comprehensive and integrated Global Action Plan on obesity, covering prevention and treatment throughout the lifecycle. Together, we can break the cycle of fragmentation and failure and use this unique opportunity to demand more, commit to more, and take a new course of action to protect the health of our populations and planet, and give the people living with or at risk of obesity the support and respect they deserve.

Competing interests: We have read and understood BMJ policy on declaration of interests. KB declares that he is a member of the WHO expert group on economic and commercial determinants of health and was commissioned by WHO in 2021 to draft messages on commercial determinants for its 2022 report on the social determinants of health. KB is a member of the policy committee of the World Obesity Federation. JR none declared.

Provenance and peer review: not commissioned, not peer reviewed.

1 Afshin A, Forouzanfar MH, Reitsma MB, etalGBD 2015 Obesity Collaborators. Health Effects of Overweight and Obesity in 195 Countries over 25 Years. N Engl J Med 2017;377:13-27. doi: 10.1056/NEJMoa1614362. pmid: 28604169

2 World Obesity Day. https://www.worldobesityday.org/policy-makers

3 Swinburn B, Egger G, Raza F. Dissecting obesogenic environments: the development and application of a framework for identifying and prioritizing environmental interventions for obesity. Prev Med 1999;29:563-70. doi: 10.1006/pmed.1999.0585. pmid: 10600438

4 Okunogbe A, Nugent R, Spencer G, Ralston J, Wilding J. Economic impacts of overweight and obesity: current and future estimates for eight countries. BMJ Glob Health 2021;6:e006351. doi: 10.1136/bmjgh-2021-006351 pmid: 34737167

5 World Obesity. Weight Stigma. https://www.worldobesity.org/what-we-do/our-policy-priorities/weight-stigma

6 Ralston J, Brinsden H, Buse K, etal. Time for a new obesity narrative. Lancet 2018;392:1384-6. doi: 10.1016/S0140-6736(18)32537-6. pmid: 30316458
7 Purdie A, Buse K, Hawkes S. Syntax and the "sin tax": the power of narratives for health. BMJ Opinion. July 2019. https://blogs.bmj.com/bmj/2019/07/17/syntax-and-the-sin-tax-the-powerof-narratives-for-health/

$8 \quad$ World Obesity. The roots of Obesity. https://www.worldobesity.org/what-we-do/our-policy-priorities/the-roots-of-obesity

9 World Helath Organization. WHO Discussion Paper: Draft recommendations for the prevention and management of obesity over the life course, including potential targets. https://www.who.int/publications/m/item/who-discussion-paper-draft-recommendations-forthe-prevention-and-management-of-obesity-over-the-life-course-including-potential-targets

10 The Bridgespan Group. Why the World Needs Both ESG and Impact Investing. https://www.bridgespan.org/insights/library/impact-investing/why-the-world-needs-both-esgand-impact-investing

11 Dolsak N, Prakash A. Climate Strikes: What They Accomplish And How They Could Have More Impact. https://www.forbes.com/sites/prakashdolsak/2019/09/14/climate-strikes-what-theyaccomplish-and-how-they-could-have-more-impact/?sh=9168dea5eeda 